\title{
PP2A promotes apoptosis and facilitates docetaxel sensitivity via the PP2A/p-eIF4B/XIAP signaling pathway in prostate cancer
}

\author{
SIWEN YIN, YONG CHEN, HANG TONG, TINGHAO LI, ZIJIA QIN, JUNLONG ZHU and WEIYANG HE \\ Department of Urology, The First Affiliated Hospital of Chongqing Medical University, Chongqing 400016, P.R. China
}

Received June 23, 2021; Accepted November 10, 2021

DOI: 10.3892/ol.2022.13221

\begin{abstract}
Serine/threonine protein phosphatase 2A (PP2A) is a protein that has a wide range of biological functions. As prostate cancer progresses from hormone-sensitive prostate cancer to castration-resistant prostate cancer (CRPC), the expression level of PP2A has been found to decrease. The present study aimed to determine the roles that PP2A may play in prostate cancer and its association with the downstream factor, $\mathrm{X}$-linked inhibitor of apoptosis (XIAP). First, the mRNA and protein expression levels of PP2A in LNCaP, DU145 and PC-3 prostate cancer cell lines were measured. Next, the population of PP2A heterodimers was increased using a PP2A agonist, DT061, in the DU145 and PC-3 cell lines. PP2A expression was then knocked down in the LNCaP cell line. Western blot analysis was performed to determine the association between PP2A, phosphorylated (p)-eukaryotic initiation factor 4B (eIF4B) and XIAP. The results revealed that following the increase in PP2A expression, the DU145 and PC-3 cell lines were more sensitive to docetaxel according to Cell Counting Kit- 8 assays and had an increased apoptotic rate as assessed by flow cytometry. Conversely, following the transfection of small interfering (si)PP2A into the LNCaP cell line, the sensitivity to docetaxel decreased, as well as the apoptotic rate. In addition, following treatment with the PP2A agonist, DT061, PP2A expression was found to be significantly upregulated, while p-eIF4B and XIAP protein expression levels were significantly downregulated. By contrast, following the transfection of siPP2A into the LNCaP cell line, PP2A protein expression levels were found to be downregulated, while p-eIF4B and XIAP expression levels were significantly upregulated. In conclusion, by affecting the downstream factor XIAP, PP2A may play a key role in promoting apoptosis and facilitating docetaxel sensitivity in prostate cancer cell lines.
\end{abstract}

Correspondence to: Professor Weiyang He, Department of Urology, The First Affiliated Hospital of Chongqing Medical University, 1 Youyi Road, Yuzhong, Chongqing 400016, P.R. China E-mail: weiyang1262020@126.com

Key words: serine/threonine protein phosphatase 2A, X-linked inhibitor of apoptosis, DT061, apoptosis, drug resistance, prostate cancer, docetaxel

\section{Introduction}

Prostate cancer is a common type of cancer in men and the second leading cause of malignant tumor-related mortality. In the United States, an estimated 26,120 deaths were attributed to prostate cancer in 2016 (1). Androgen deprivation therapy (ADT) has been shown to be an effective treatment for prostate cancer, proving indispensable for advanced-stage prostate cancer (2-4). However, the majority of prostate cancer cases develop into castration-resistant prostate cancer (CRPC) following ADT within 2 years $(5,6)$, despite the circulating testosterone levels being decreased to 'castrate level'. CRPC is associated with poor survival rates, and currently, no effective methods exist to prevent progression (7). Therefore, determining the molecular mechanism that promotes CRPC and identifying novel targets for CRPC treatment are important.

Serine/threonine protein phosphatase 2A (PP2A) is a tumor-suppressive factor that has been discovered to participate in numerous signaling pathways, including PI3K/Akt/mTOR, $\mathrm{Wnt} / \beta$-catenin and c-Myc pathways (8). It was previously reported that the deregulation of PP2A and its regulatory subunits was commonly observed in breast cancer, and such an event was associated with an unfavorable outcome (9). The subsequent restoration of $\mathrm{PP} 2 \mathrm{~A}$, due to its functional deficiency in colorectal cancer, was also revealed to enhance the patient response to chemotherapy (10). The expression levels of PP2A have been found to be downregulated in various types of cancer, such as breast (9), colorectal (10) and lung cancer (11), as well as acute myeloid leukemia (12); however, to the best of our knowledge, few studies have reported the changes in the expression levels during prostate cancer tumorigenesis and its effect on apoptosis and chemoresistance. Therefore, determining the effect of PP2A on the development of prostate cancer is of great significance.

$\mathrm{X}$-linked inhibitor of apoptosis (XIAP) is an antiapoptotic factor whose expression has been found to be upregulated in various types of cancer, such as bladder cancer (13), renal cell carcinoma (14) and acute myeloid leukemia (15). The upregulated expression of XIAP was reported in ovarian carcinoma and esophageal carcinoma cell lines, which were found to be insensitive to chemotherapy $(16,17)$. A previous study also demonstrated that the expression levels of XIAP were markedly upregulated in CRPC tissues and cells compared with those in androgen-sensitive tissues and cells (18). PP2A participates in the cell cycle and 
apoptosis (19). Previous research revealed that dephosphorylation of eukaryotic initiation factor 4B (eIF4B) at serine 406 was mediated by PP2A (20). In addition, another study revealed that pim-2 proto-oncogene serine/threonine kinase (Pim-2) was upregulated in prostate cancer, and suggested that the Pim-2/eIF4B/XIAP signaling pathway may participate in the progression of prostate cancer (21). Furthermore, Pim-2 was discovered to directly phosphorylate eIF4B on serine 406 (22), which indicated that XIAP may be a downstream factor of eIF4B. Thus, determining the downstream factor of eIF4B within the PP2A signaling pathway and the antiapoptotic effect of PP2A are of critical importance. The present study investigated whether restoration of PP2A promotes apoptosis and facilitates docetaxel sensitivity via the PP2A/p-eIF4B/XIAP signaling pathway in prostate cancer.

\section{Materials and methods}

Cell culture and treatment. The human prostate cancer cell line, LNCaP, was purchased from Shanghai Biowing Applied Biotechnology Co. Ltd. The DU145 and PC-3 cell lines were purchased from Shanghai Zhong Qiao Xin Zhou Biotechnology Co., Ltd. The LNCaP cell line was cultured in RPMI-1640 medium (Corning, Inc.) and supplemented with 10\% FBS (Gibco; Thermo Fisher Scientific, Inc.). The DU145 and PC-3 cell lines were cultured in Eagle's Minimum Essential Medium (cat. no. ZQ-301; Shanghai Zhong Qiao Xin Zhou Biotechnology Co., Ltd.), supplemented with Earle's salts, L-glutamine, non-essential amino acids, $\mathrm{NaHCO}_{3}, 10 \%$ FBS and $1 \%$ penicillin-streptomycin. All the cell lines were maintained at $37^{\circ} \mathrm{C}$ in a humidified incubator with $5 \% \mathrm{CO}_{2}$. Trypsin was used for cell dissociation (HyClone; Cytiva).

To increase the expression level of PP2A, an agonist of PP2A, DT061 (10 $\mu \mathrm{mol} / 1$; cat. no. 112929; MedChemExpress), was used to treat the DU145 and PC-3 cell lines. DT061 was dissolved in DMSO $(10 \mu \mathrm{mol} / \mathrm{l})$. The control group contained cells treated with DMSO only. All the cell lines were maintained at $37^{\circ} \mathrm{C}$ in a humidified incubator with $5 \% \mathrm{CO}_{2}$ for $48 \mathrm{~h}$. The cell lines were also treated with increasing concentrations of docetaxel $(0.00,0.05,0.50,1.00,2.00,5.00,50.00,200.00$ and $500.00 \mathrm{nM}$; cat. no. HY-B0011; MedChemExpress) at $37^{\circ} \mathrm{C}$ for $48 \mathrm{~h}$.

Cell transfection. Cell transfection was performed at $37^{\circ} \mathrm{C}$ for $6 \mathrm{~h}$ using Lipofectamine ${ }^{\circledR} 2000$ (Invitrogen; Thermo Fisher Scientific, Inc.). Subsequent experimentation was performed $48 \mathrm{~h}$ after transfection, according to the manufacturer's protocol. Briefly, the LNCaP cell line was seeded into six-well plates, at a density of $1.2 \times 10^{5}$ cells/well, and upon reaching $65-70 \%$ confluence, the medium was changed to 2 ml RPMI-1640 medium (Gibco; Thermo Fisher Scientific, Inc.), supplemented with $5 \mu \mathrm{l}$ Lipofectamine 2000 reagent and $5 \mu \mathrm{l}(20 \mu \mathrm{M})$ small interfering (si)RNA. The siRNAs used, which were purchased from Shanghai GenePharma Co., Ltd. (cat. no. A10001), were as follows: siPP2A-1 (siRNA1), 5'-CAC CGA AUUUAUGGGAAAUTT-3'; siPP2A-2 (siRNA2), 5'-GGGCAUUGUACUUCUGGAATT-3'; siPP2A-3 (siRNA3), 5'-GACCUUACUAGCUCAUACATT-3'; and si-negative control (NC), 5'-UUCUCCGAACGUGUCACGUTT 3'. The siRNA used in the cell transfection was siPP2A-2 (siRNA2). The NC siRNA used was a scramble non-targeting sequence.

Cell Counting Kit (CCK)-8 assay. Cell viability was analyzed using a CCK-8 assay (Dojindo Molecular Technologies, Inc.). Briefly, the DU145 and PC-3 cell lines were treated with $10 \mu \mathrm{M}$ DT061 (dissolved in DMSO) at $37^{\circ} \mathrm{C}$ for $48 \mathrm{~h}$, then seeded into 96-well flatbottomed microplates, at a density of $5 \times 10^{3}$ cells/well. Increasing concentrations $(0,0.05,0.5,1,2,5$, 50,200 and $500 \mathrm{nM}$ ) of docetaxel were subsequently added to each well and the cells were incubated at $37^{\circ} \mathrm{C}$ for $48 \mathrm{~h}$; each well contained a volume of $100 \mu \mathrm{l}$, consisting of $90 \mu \mathrm{l}$ cell suspension and $10 \mu \mathrm{l}$ docetaxel solution. Following incubation for $48 \mathrm{~h}$ at $37^{\circ} \mathrm{C}, \mathrm{CCK}-8$ reagent was added to each well at $37^{\circ} \mathrm{C}$ for $1 \mathrm{~h}$ and the absorbance was measured at $450 \mathrm{~nm}$.

For the LNCaP cell line, the cells were first transfected with siRNA at $37^{\circ} \mathrm{C}$ for $48 \mathrm{~h}$, then seeded into 96-well flatbottomed microplates, at a density of $5 \times 10^{3}$ cells/well. Next, docetaxel was added to each well at gradient concentrations $(0,0.05,0.5$, $1,2,5,50,200$ and $500 \mathrm{nM})$. Following incubation at $37^{\circ} \mathrm{C}$ for $48 \mathrm{~h}, \mathrm{CCK}-8$ reagent was added to each well and the cells were incubated at $37^{\circ} \mathrm{C}$ for $1 \mathrm{~h}$, and the absorbance was measured at $450 \mathrm{~nm}$.

Reverse transcription-quantitative PCR (RT-qPCR). Total RNA was extracted from the DU145, PC-3 and LNCaP cell lines. using TRIzol ${ }^{\circledR}$ (Takara Biotechnology Co., Ltd.). SYBR Green was used as the fluorophore (MedChemExpress). Total RNA was reverse transcribed into cDNA using random primers and a RT Master Mix for qPCR (gDNA digester plus), according to the manufacture's protocol (cat. no. HY-K0511; MedChemExpress). The following thermocycling conditions were used for RT: $25^{\circ} \mathrm{C}$ for $5 \mathrm{mins}, 42^{\circ} \mathrm{C}$ for $40 \mathrm{mins}$ and $85^{\circ} \mathrm{C}$ for 2 mins. The following thermocycling conditions were used for qPCR: Initial denaturation at $94^{\circ} \mathrm{C}$ for $2 \mathrm{~min}$, followed by 35 cycles at $94^{\circ} \mathrm{C}$ for $40 \mathrm{sec}, 50^{\circ} \mathrm{C}$ for $40 \mathrm{sec}$ and $72^{\circ} \mathrm{C}$ for $1 \mathrm{~min}$ and final extension at $72^{\circ} \mathrm{C}$ for $5 \mathrm{~min}$. PP2A expression was subsequently determined using $\mathrm{qPCR}$ and the following primers: Human PP2A forward, 5'-AGAAGAGGATGAACC CACGC-3' and reverse, 5'-TGCTAGGCTGGAAATCAG GG-3'; and GAPDH forward, 5'-CCTTCCGTGTCCCCACT-3' and reverse, 5'-GCCTGCTTCACCACCTTC-3'. GAPDH expression was used as the internal control for normalization. The $2^{-\Delta \Delta \mathrm{Cq}}$ method was used for the quantification of the expression levels (23).

Western blot analysis. Total protein was extracted from the DU145, PC-3 and LNCaP cell lines using RIPA lysis buffer (Beyotime Institute of Biotechnology) and centrifuged at $12,000 \times \mathrm{g}$ for $20 \mathrm{~min}$ at $4^{\circ} \mathrm{C}$. Total protein was quantified using a BCA protein assay kit (Beyotime Institute of Biotechnology) and $30 \mu \mathrm{g}$ protein/lane was separated on $10-12 \%$ gels using SDS-PAGE at a constant voltage of $95 \mathrm{~V}$. The separated proteins were subsequently transferred onto PVDF membranes (MilliporeSigma) and blocked with 5\% skimmed milk at $25^{\circ} \mathrm{C}$ for $2 \mathrm{~h}$. The membranes were then incubated overnight at $4^{\circ} \mathrm{C}$ with the following primary antibodies: Anti-PP2A (cat. no. 12675-2-AP; dilution, 1:500), anti-XIAP (cat. no. 66800-1-Ig; dilution, 1:5,000), anti-Bax 
A

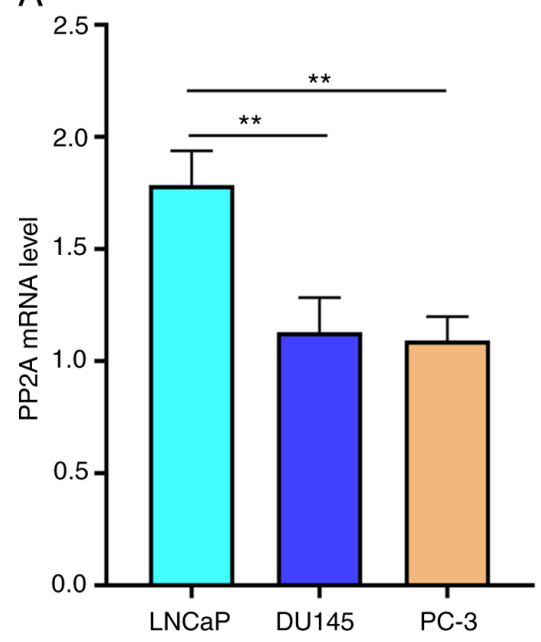

B

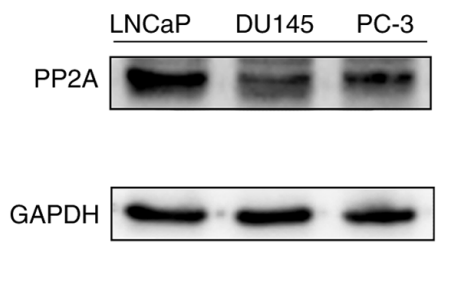

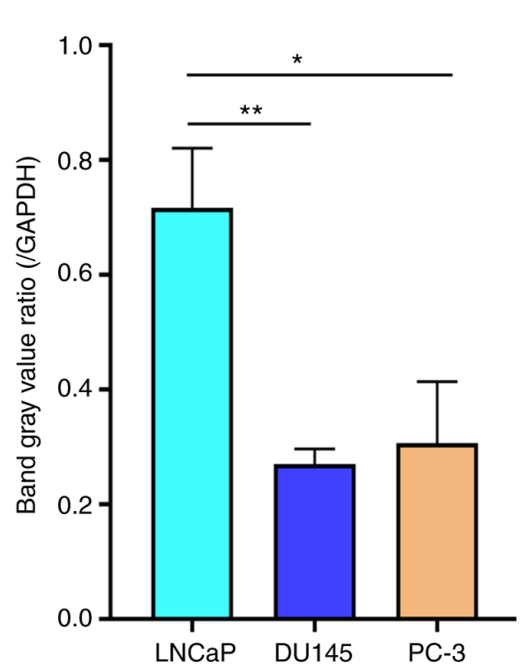

Figure 1.PP2A (A) mRNA and (B) protein expression levels in the LNCaP, DU145 and PC-3 cell lines. ${ }^{*} \mathrm{P}<0.05,{ }^{* *} \mathrm{P}<0.01$ vs. LNCaP cell line. PP2A, serine/threonine protein phosphatase $2 \mathrm{~A}$.

(cat. no. 50599-2-Ig; dilution, 1:1,000) and anti-Bcl-2 (cat. no. 12789-1-AP; dilution, 1:1,000) (all ProteinTech Group, Inc.), anti-phosphorylated (p)-eIF4B (cat. no. R26284; dilution, 1:5,000; Chengdu Zen Bioscience Co., Ltd), anti-eIF4B (cat. no. R26713; dilution, 1:5,000; Chengdu Zen Bioscience Co., Ltd), anti-GAPDH (cat. no. AB0037; dilution, 1:3,000; Shanghai Abways Biotechnology Co., Ltd.;) and anti-cleaved caspase-3 (cat. no. 9664; dilution, 1:1,000; Cell Signaling Technology, Inc.). Following incubation with the primary antibodies, the membranes were incubated with an HRP-conjugated secondary antibody (cat. no. 91196; dilution, 1:2,000; Cell Signaling Technology, Inc.) at $25^{\circ} \mathrm{C}$ for $1 \mathrm{~h}$. The protein bands were visualized using an ECL system (GelDoc Go; Bio-Rad Laboratories, Inc.). The blots were quantified using Evolution (version number:18.0.8.0, Viber Lourmat).

Flow cytometric analysis of apoptosis. Cell apoptosis (early + late apoptotic cells) was analyzed $48 \mathrm{~h}$ after treatment. LNCaP cells were transfected with siPP2A or si-NC $(5 \mu \mathrm{l} ; 20 \mu \mathrm{M})$ at $37^{\circ} \mathrm{C}$ for $6 \mathrm{~h}$ in the presence or absence of subsequent $5 \mathrm{nmol} / 1$ docetaxel treatment. DU145 and PC-3 cells were treated with $10 \mu \mathrm{mol} / 1$ DT061 (dissolved in DMSO), $5 \mathrm{nmol} / 1$ docetaxel, $10 \mu \mathrm{mol} / 1$ DT061 (dissolved in DMSO) $+5 \mathrm{nmol} / 1$ docetaxel at $37^{\circ} \mathrm{C}$ for $48 \mathrm{~h}$; the control group was treated with DMSO. The treated cells were subsequently trypsinized and resuspended in $\mathrm{PBS}$, then stained using reagents from the Annexin V-FITC/PI Apoptosis Detection kit (cat. no. 556570; BD Biosciences), according to the manufacturer's protocol. CytoFLEX V2-B4-R0 Flow Cytometer (cat. no. C02944; Beckman Coulter) and CytExpert software were used for analysis (version no. 2.4.0.28; Beckman Coulter, Inc.).

Statistical analysis. All the experiments were performed three times. Statistical analysis was performed using SPSS v22.0 software (IBM Corp.) and the data are presented as the mean \pm SD. Statistical differences between groups (unpaired) were determined using a Student's t-test or one-way ANOVA followed by Tukey's post hoc test. $\mathrm{P}<0.05$ was considered to indicate a statistically significant difference.

\section{Results}

PP2A expression is decreased in CRPC cells. To determine the mRNA and protein expression level of PP2A in different prostate cancer cell lines, including LNCaP cells (sensitive to ADT), and the DU145 and PC-3 cells (insensitive to ADT), RT-qPCR and western blot analysis were performed, respectively. The mRNA expression levels of PP2A were significantly increased in LNCaP cells compared with those in the DU145 and PC-3 cell lines (Fig. 1A). Similarly, western blot analysis revealed that the protein expression levels of PP2A were also significantly increased in LNCaP cells compared with those in the DU145 and PC-3 cell lines (Fig. 1B). These results indicated that the expression level of PP2A was lower in AR-negative cell lines than AR-positive cell lines.

Increase in PP2A expression promotes cell apoptosis and drug sensitivity to docetaxel. To investigate the biological role of PP2A in cell apoptosis and drug resistance, flow cytometry and CCK-8 assays were performed. The small molecule, DT061 (10 $\mu \mathrm{mol} / \mathrm{l}$; dissolved in DMSO), which is able to increase the population of PP2A heterotrimers (24), was used to upregulate PP2A expression levels in the CRPC cell lines, DU145 and PC-3 (Fig. 2A and B). The control group contained cells treated with DMSO. Flow cytometric analysis of apoptosis revealed that DT061 increased the apoptosis rate compared with the control (DMSO). Treatment with DT061 combined with docetaxel $(5 \mathrm{nmol} / \mathrm{l})$ significantly increased the apoptotic rate compared to the Docetaxel group (5 nmol/l) in both the DU145 and PC-3 cell lines (Fig. 2C and D). The results of western blot analysis demonstrated that the protein expression level of Bcl-2 was decreased in the DT061 group compared with that in the control group, while the expression levels of Bax and cleaved caspase- 3 were increased in the DT061 group compared with those in the control group in both the DU145 and PC-3 cell lines (Fig. 2E and F). The results of the CCK-8 assay found that the CRPC cell lines (DU145 and PC-3) in the DT061 group had significantly increased sensitivity to docetaxel compared with the cell lines in the 


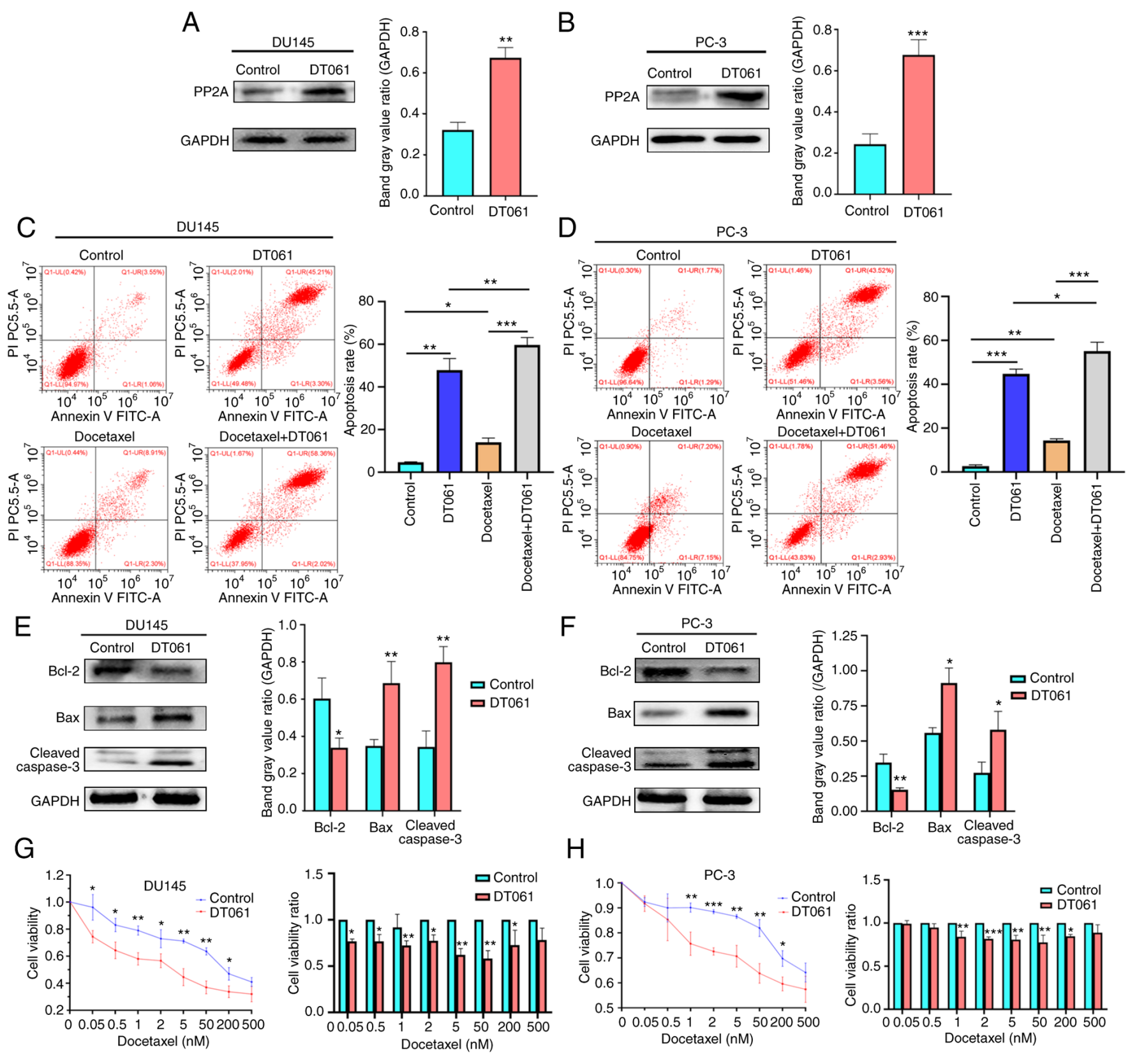

Figure 2. PP2A protein expression levels in the (A) DU145 and (B) PC-3 cells treated with DT061 were analyzed using western blot analysis. ${ }^{* *} \mathrm{P}<0.01$, ${ }_{* * * *} \mathrm{P}<0.001$ vs. control. Apoptotic rate of (C) DU145 and (D) PC-3 cells following treatment with docetaxel and DT061 was analyzed using flow cytometry. ${ }^{*} \mathrm{P}<0.05,{ }^{* *} \mathrm{P}<0.01,{ }^{* * *} \mathrm{P}<0.001$. (E) DU145 and (F) PC-3 cells were treated with DT061 and the protein expression levels of Bax, Bcl-2 and cleaved caspase-3 were analyzed using western blot analysis. ${ }^{*} \mathrm{P}<0.05,{ }^{* *} \mathrm{P}<0.01$ vs. control. Viability of (G) DU145 and (H) PC-3 cells treated with DT061 was decreased compared with that in the control group. ${ }^{*} \mathrm{P}<0.05,{ }^{* *} \mathrm{P}<0.01,{ }^{* * * *} \mathrm{P}<0.001$ vs. control. PP2A, serine/threonine protein phosphatase $2 \mathrm{~A}$.

control group (Fig. 2G and $\mathrm{H}$ ). These results indicated that DT061 may upregulate the expression levels of PP2A, which may promote cell apoptosis and drug sensitivity to docetaxel in the CRPC cell lines.

PP2A knockdown supresses cell apoptosis and enhances the tolerance to docetaxel. To further validate the role that PP2A may play in apoptosis, drug resistance and the development of prostate cancer, the $\mathrm{LNCaP}$ cell line was transfected with siPP2A to knock down its expression (Fig. 3A and B), then flow cytometry, western blot analysis and a CCK-8 assay were performed. Flow cytometric analysis of apoptosis found that knockdown of PP2A decreased the apoptotic rate in the LNCaP cells (Fig. 3C). The siRNA used in the transfection was siRNA2. The results of western blot analysis revealed that the expression level of Bcl-2 was increased in the siPP2A group compared with that in the si-NC group. By contrast, the expression levels of Bax and cleaved caspase- 3 were decreased in the siPP2A group compared with those in the si-NC group (Fig. 3D).

PP2A expression was knocked down in the LNCaP cells, which were then treated with docetaxel $(0.5-500 \mathrm{nM})$ for $48 \mathrm{~h}$, and cell viability was measured using a CCK-8 assay. The results demonstrated that the siPP2A group exhibited enhanced tolerance to docetaxel (Fig. 3E). These findings suggested that PP2A knockdown supresses cell apoptosis and enhances the tolerance to docetaxel. 
A

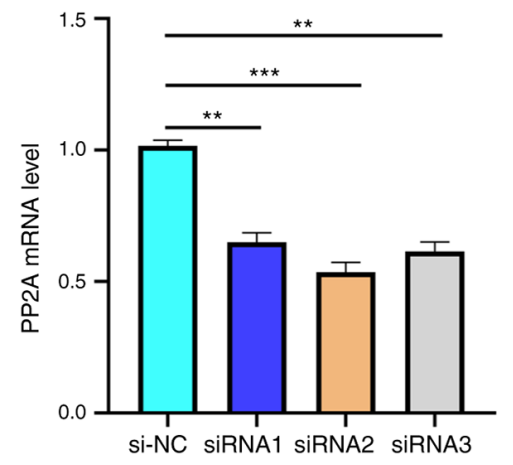

B

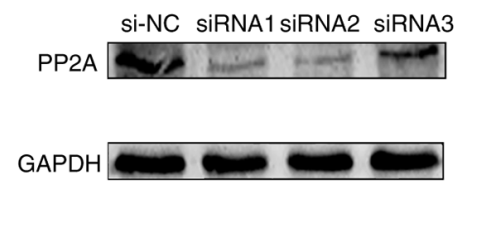

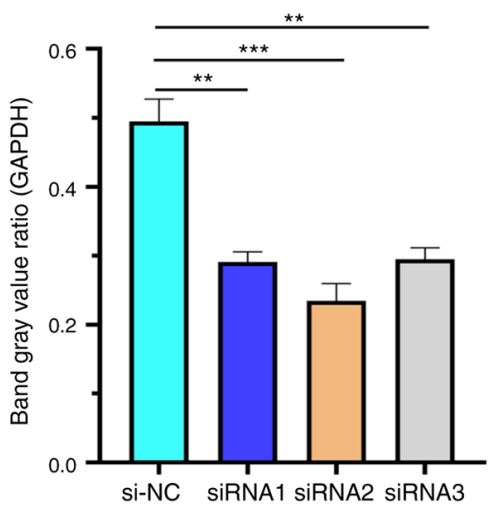

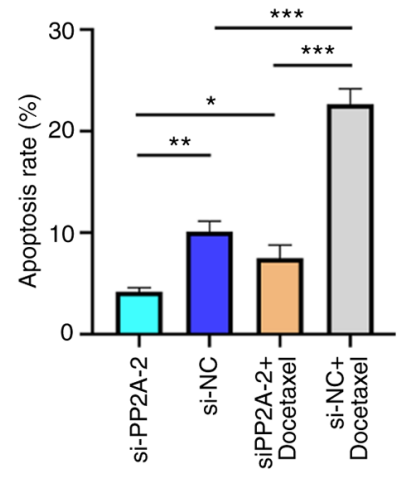

E

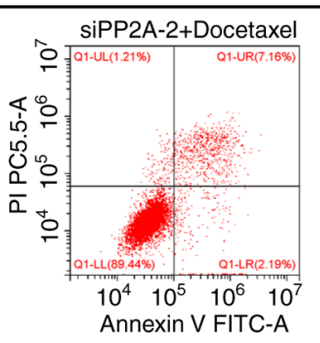

E

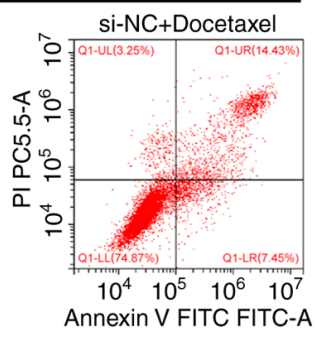

Annexin V FITC FITC-A
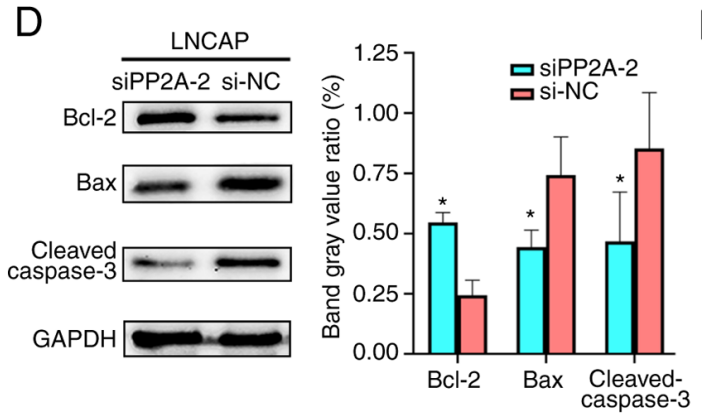
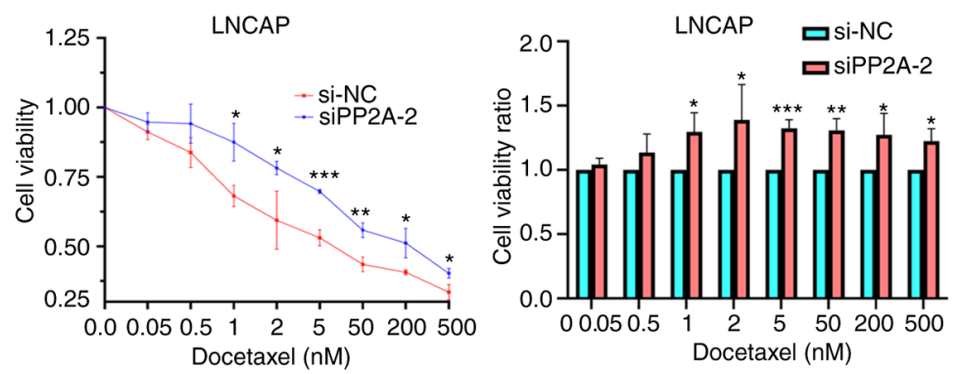

Figure 3. PP2A (A) mRNA and (B) protein expression levels in the LNCaP cell line transfected with siPP2A. ${ }^{* *} \mathrm{P}<0.01,{ }^{* * *} \mathrm{P}<0.001$ vs. siNC. (C) Apoptotic rate of LNCaP cells treated with docetaxel and transfected with siPP2A was analyzed using flow cytometry. ${ }^{*} \mathrm{P}<0.05$, ${ }^{* *} \mathrm{P}<0.01,{ }^{* * * *} \mathrm{P}<0.001$. (D) $\mathrm{Protein}$ expression levels of Bax, Bcl-2 and cleaved caspase-3 in the LNCaP cell line transfected with siPP2A. * $\mathrm{P}<0.05$ vs. siNC. (E) Cell viability in the cells transfected with siRNA was increased compared with that in the $\mathrm{NC}$ group. ${ }^{*} \mathrm{P}<0.05,{ }^{* *} \mathrm{P}<0.01,{ }^{* * *} \mathrm{P}<0.001$ vs. NC. PP2A, serine/threonine protein phosphatase $2 \mathrm{~A}$; $\mathrm{NC}$, negative control; si, small interfering RNA.

$X I A P$ expression is associated with the expression level of PP2A. To determine the association between PP2A and XIAP, PP2A expression was increased or knocked down, then western blot analysis was performed to determine changes in the protein expression levels of p-eIF4B and XIAP. In the DU145 and PC-3 cell lines, when DT061 was used to increase the expression level of PP2A, the protein expression levels of p-eIF4B and XIAP were found to be significantly decreased compared with those in the si-NC group (Fig. 4A-D). By contrast, when the expression level of PP2A was knocked down in the LNCaP cells using siPP2A, the protein expression levels of p-eIF4B and XIAP were increased compared with those in the si-NC group (Fig. 4E and F). These results indicated that the change in $\mathrm{PP} 2 \mathrm{~A}$ expression may regulate the expression level of XIAP via the PP2A/eIF4B/XIAP signaling pathway.

\section{Discussion}

As the terminal stage of prostate cancer, CRPC has been associated with a high metastatic rate, chemotherapy resistance and poor survival rates. The median survival time of patients with CRPC was recorded as $8.6 \pm 10.6$ in the Netherlands (25), 13.0 in the USA (26), 14.5 months in Italy (27). A previous study revealed that $83.8 \%$ of patients in Japan were shown to have metastases at diagnosis (28). Over the past 30 years, numerous potential drugs for CRPC have emerged, such as cabazitaxel $(29,30)$, abiraterone acetate $(31,32)$ and enzalutamide (33), rendering the treatment regimen of the disease more flexible and diverse. However, the curative effect of CRPC is far from satisfactory, particularly for patients with metastatic (m)CRPC (34). Significant effort has been made to improve the prognosis of these patients; however, efficient and effective therapies have not yet been developed (34). Unlike other types of cancer, such as bladder and kidney cancer, the dependence of prostate cancer on androgens for propagation and growth make it unique. Therefore, ADT is widely used in clinical practice and has been shown to be effective (35). CRPC is described as prostate cancer that has progressed despite ADT. However, to the best of our knowledge, the process through which prostate cancer cells 
A

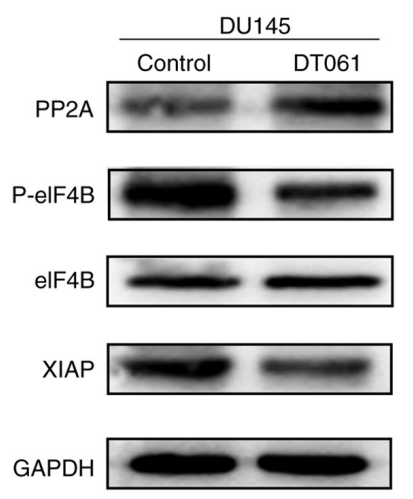

C

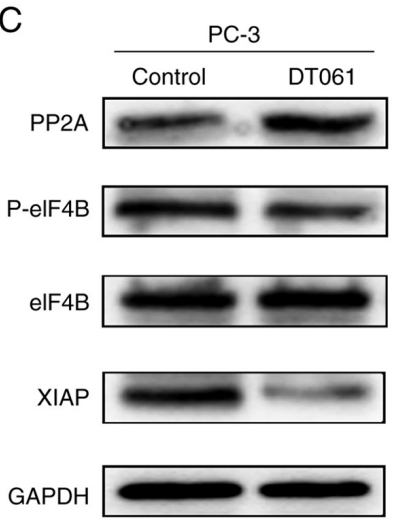

$\mathrm{E}$
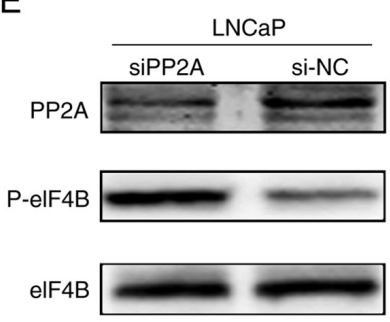

XIAP

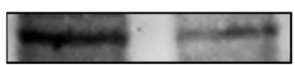

GAPDH

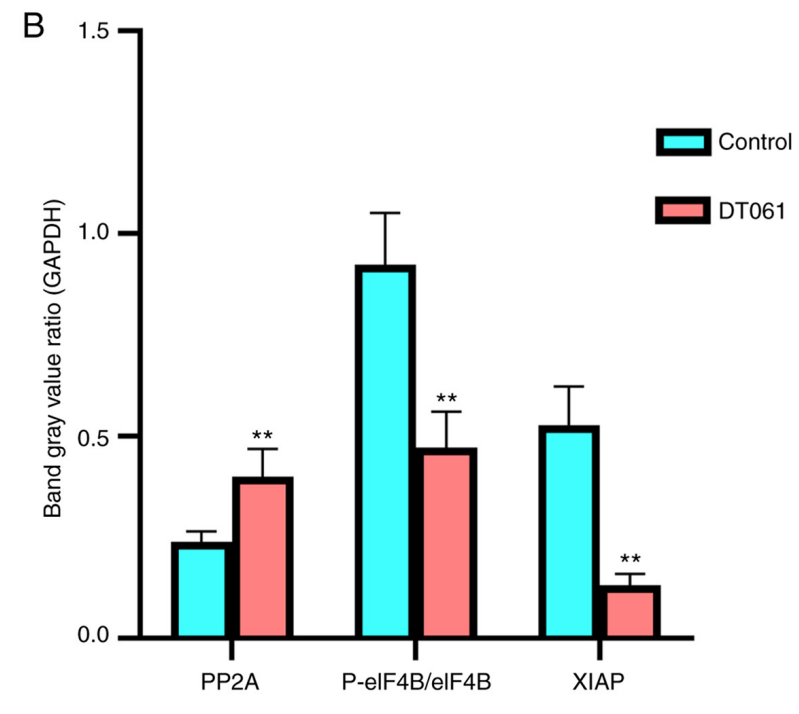

D
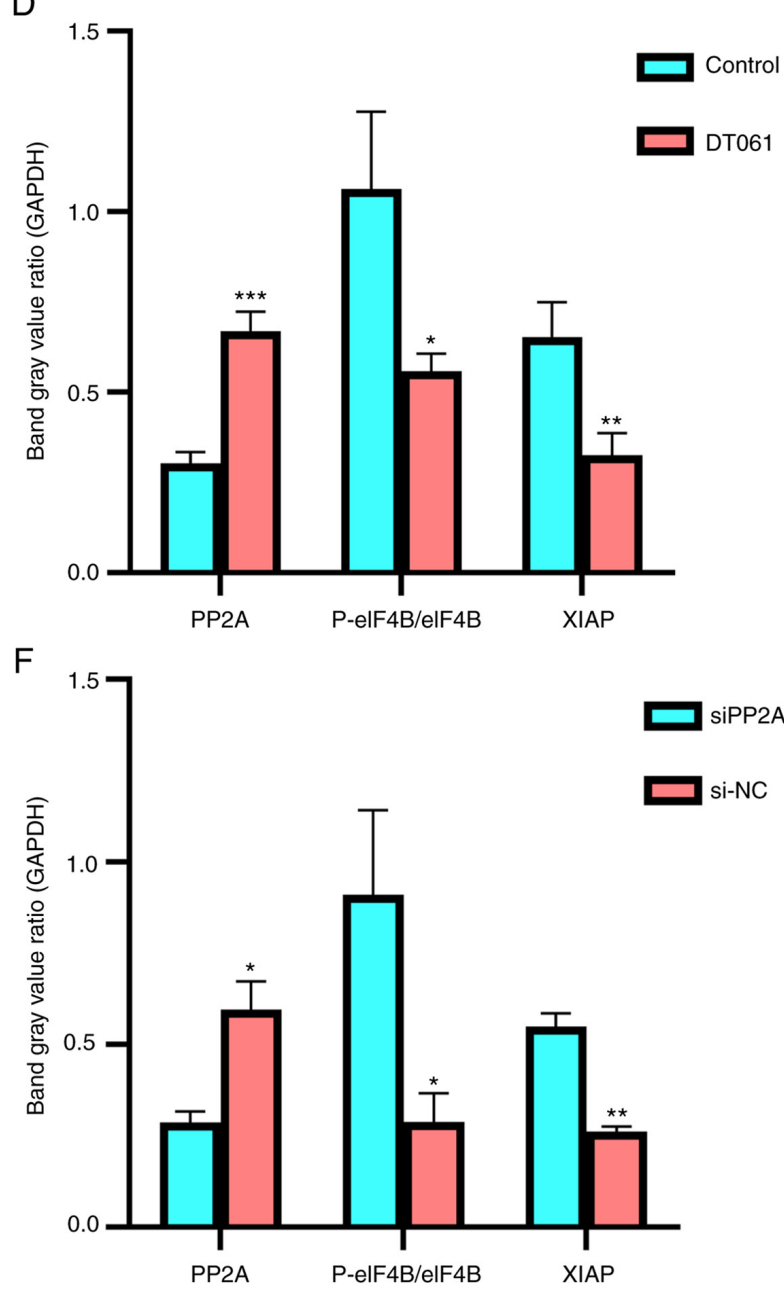

Figure 4. PP2A, p-eIF4B, eIF4B and XIAP protein expression levels in (A and B) DU145 and (C and D) PC-3 cells treated with DT061. ${ }^{*} \mathrm{P}<0.05,{ }^{* *} \mathrm{P}<0.01$, ${ }^{* * * *} \mathrm{P}<0.001$ vs. control. (E) PP2A, P-eIF4B/eIF4B, XIAP protein expression levels in the LNCaP cell line transfected with siPP2A and the results were subsequently (F) quantified using densitometry. ${ }^{*} \mathrm{P}<0.05,{ }^{* * *} \mathrm{P}<0.01$ vs. siNC. PP2A, serine/threonine protein phosphatase $2 \mathrm{~A}$; NC, negative control; si, small interfering RNA; $p$, phosphorylated; XIAP, X-linked inhibitor of apoptosis; eIF4B, eukaryotic initiation factor 4B.

become castrate-resistant is not yet completely understood. It has been suggested that ADT may inhibit the proliferation of androgen-dependent cells. This then allows androgen-independent cells to become the new dominant primary tumor cells (36). Another study has indicated that androgen receptor amplification and hypersensitivity/mutations may play a key role in this process (2). However, treatment for CRPC is difficult; therefore, it remains of utmost importance to understand the underlying mechanisms of CRPC development. 
Accumulating data have demonstrated that PP2A activation is of great significance in prostate cancer. A previous study showed that PP2A activation could suppress prostate tumor growth and metastasis (37). PP2A activation inhibited the growth of androgen-independent prostate cancer cells (38). On the other hand, downregulation of PP2A enhanced metastatic ability and led to higher mortality in prostate cancer $(39,40)$. These results indicate that $\mathrm{PP} 2 \mathrm{~A}$ activation is promising in the treatment of prostate cancer. The results of the present study found that the mRNA and protein expression levels of PP2A were decreased in prostate cancer cells, as the tumor cells transitioned from non-CRPC cells to CRPC cells. The knockdown of PP2A expression was subsequently found to promote CRPC cell chemoresistance and inhibit apoptosis. A previous study found that treatment with the PP2A activators, forskolin and FTY720, exerted antitumor effects and affected the proliferation of the PC-3 cell line (41). To determine the effect of activated PP2A on CRPC cells in the current study, the population of PP2A heterotrimers was increased by treatment with another PP2A activator, DT061 $(11,24,42)$ in the DU145 and PC-3 cell lines. The results revealed that the CRPC cells exhibited higher apoptotic rates. In addition, the protein expression levels of the apoptosis-related proteins, Bax and cleaved caspase-3, were upregulated, while the protein expression level of Bcl-2 was downregulated. These results indicated that DT061 may regulate the expression level of apoptosis-related proteins to promote cell apoptosis. For patients with $\mathrm{mCRPC}$, docetaxel remains the first-line treatment method (43). However, once resistance to docetaxel emerges, the therapeutic benefit is limited, which leads to therapeutic failure (2). In the present study, the results of the CCK-8 assay revealed that CRPC cells treated with DT061 showed an enhanced sensitivity to docetaxel. These results suggested that DT061 may ameliorate docetaxel resistance and be of potential benefit for patients with CRPC.

The functional loss of PP2A serves a key role in tumorigenesis. For example, a previous study found that protein expression levels of PP2A-Aa and PP2A-Ba are markedly decreased in breast cancer tissue and the knockdown of PP2A-Ba enhances proliferation in MCF7 breast cancer cells (44). PP2A complexes consist of structural (PP2A-A), regulatory (PP2A-B), and catalytic (PP2A-C) subunits (24). The PP2A subunits may vary in different cell lines, which may cause the PP2A protein to exhibit split bands when examined using western blot analysis. In the present study, to further investigate the roles that PP2A played in the progression of prostate cancer and its association with apoptosis and chemoresistance, siPP2A was transfected into the AR-positive cell line, LNCaP. The results revealed that the apoptotic rate was decreased following the knockdown of PP2A expression, which indicated that PP2A knockdown may play a vital role in the promotion of cell propagation. Similarly, the results of the CCK-8 assay revealed that the transfection of siPP2A into the LNCaP cell line increased the resistance of the cells to docetaxel. These results suggested that the knockdown of PP2A may decrease the curative effect of docetaxel.

The activation of PP2A has been considered as a promising therapeutic strategy in various types of cancer, including acute myeloid leukemia (45), KRAS-mutant lung cancer (46) and prostate cancer (47); however, to the best of our knowledge, the underlying mechanism of action of PP2A has not been fully determined. Previous studies revealed that a PP2A agonist increased the levels of apoptosis by downregulating cellular inhibitor of PP2A expression levels $(48,49)$. Another study revealed that PP2A activation downregulated the phosphoproteome and weakened the stability of the androgen receptor in CRPC (50). The findings of the current study revealed that, when the expression level of PP2A was increased, the protein expression levels of p-eIF4B and XIAP were decreased. By contrast, when PP2A expression was knocked down, p-eIF4B and XIAP protein expression levels were increased. These results indicated that XIAP may be a downstream factor of PP2A and that the PP2A/p-eIF4B/XIAP signaling pathway may participate in the development of prostate cancer. There are numerous apoptosis-related pathways that are modulated or mediated by PP2A. For example, the PP2A activator, FTY720, was able to induce ferroptosis and promote multiple myeloma cell apoptosis by activating the PP2A/AMP-activated protein kinase pathway (51). In addition, PP2A was able to regulate the ERK, p38 MAPK and Akt signaling pathways to enhance apoptosis in lung cancer cells (52). However, to the best of our knowledge, whether DT061 affects these pathways remains undetermined, and further research is required to investigate the effect of PP2A activation induced by DT061. Furthermore, only in vitro not in vivo experiments were performed, which is a limitation to the present study. PP2A knockdown is known to play a key role in malignant cell proliferation and drug resistance (44). However, few studies have revealed the effect of PP2A knockdown on apoptosis and docetaxel resistance in prostate cancer. In a previous study, a longer overall survival time was observed in patients with mCRPC when treated with docetaxel compared with that in patients treated with mitoxantrone; however, docetaxel therapy was limited as a result of the emergence of tumor resistance (53). There have been numerous explanations underlying the emergence of docetaxel resistance, including the overexpression of multidrug resistance genes, tubulin alterations, the presence of androgen receptor variants and the occurrence of epithelial-mesenchymal transition (53). In the present study, XIAP protein expression levels were found to be regulated by PP2A; however, the mechanism by which the altered expression of XIAP resulted in docetaxel resistance remains unclear. A previous study found that downregulated protein expression levels of XIAP was associated with drug resistance in the DU145 cell line (54). XIAP inhibition led to an increase in caspase-3 activity and decreased cell viability, which rendered CRPC cells more sensitive to chemotherapy (54). Therefore, we hypothesized that the anti-apoptotic effect of XIAP may enhance the viability of CRPC cells and result in docetaxel resistance.

In conclusion, the findings of the current study indicated that PP2A may play a vital role in the development of CRPC. $\mathrm{PP} 2 \mathrm{~A}$ was discovered to decrease XIAP protein expression levels via the PP2A/p-eIF4B/XIAP signaling pathway, which promoted apoptosis and improved cell resistance to docetaxel. Therefore, the activation of PP2A may represent a novel therapeutic approach for the treatment of CRPC.

\section{Acknowledgements}

Not applicable. 


\section{Funding}

The present study was supported by a grant from the Chongqing Basic Science and Advanced Technology Research Program (grant no. cstc2017jcyjAX0049).

\section{Availability of data and materials}

The datasets used and/or analyzed during the current study are available from the corresponding author on reasonable request.

\section{Authors' contributions}

WH and SY contributed to the conception and design of the study. SY and HT performed the experiments. JZ and ZQ collected the data. JZ and ZQ confirm the authenticity of all the raw data. TL, JZ, ZQ and YC performed the statistical analysis. SY wrote the first draft of the manuscript. SY, YC and HT contributed to the writing of the manuscript. All authors have read and approved the final manuscript.

\section{Ethics approval and consent to participate}

Not applicable.

\section{Patient consent for publication}

Not applicable.

\section{Competing interests}

The authors declare that they have no competing interests.

\section{References}

1. Ritch CR and Cookson MS: Advances in the management of castration resistant prostate cancer. BMJ 355: i4405, 2016.

2. Chandrasekar T, Yang JC, Gao AC and Evans CP: Mechanisms of resistance in castration-resistant prostate cancer (CRPC). Transl Androl Urol 4: 365-380, 2015.

3. Harris WP, Mostaghel EA, Nelson PS and Montgomery B: Androgen deprivation therapy: Progress in understanding mechanisms of resistance and optimizing androgen depletion. Nat Clin Pract Urol 6: 76-85, 2009.

4. Pienta KJ and Bradley D: Mechanisms underlying the development of androgen-independent prostate cancer. Clin Cancer Res 12: 1665-1671, 2006.

5. Mohler JL, Gregory CW, Ford OH III, Kim D, Weaver CM, Petrusz P, Wilson EM and French FS: The androgen axis in recurrent prostate cancer. Clin Cancer Res 10: 440-448, 2004.

6. Agoulnik IU and Weigel NL: Androgen receptor action in hormone-dependent and recurrent prostate cancer. J Cell Biochem 99: 362-372, 2006.

7. Shafi AA, Yen AE and Weigel NL: Androgen receptors in hormone-dependent and castration-resistant prostate cancer. Pharmacol Ther 140: 223-238, 2013.

8. Grech G, Baldacchino S, Saliba C, Grixti MP, Gauci R, Petroni V, Fenech AG and Scerri C: Deregulation of the protein phosphatase 2A, PP2A in cancer: Complexity and therapeutic options. Tumour Biol 37: 11691-11700, 2016.

9. Baldacchino S, Saliba C, Petroni V, Fenech AG, Borg N and Grech G: Deregulation of the phosphatase, PP2A is a common event in breast cancer, predicting sensitivity to FTY720. EPMA J 5: 3, 2014.

10. Cristóbal I, Manso R, Rincón R, Caramés C, Senin C, Borrero A Martínez-Useros J, Rodriguez M, Zazo S, Aguilera O, et al: PP2A inhibition is a common event in colorectal cancer and its restoration using FTY720 shows promising therapeutic potential. Mol Cancer Ther 13: 938-947, 2014
11. Kauko O, Connor CM, Kulesskiy E, Sangodkar J, Aakula A, Izadmehr S, Yetukuri L, Yadav B, Padzik A, Laajala TD, et al: PP2A inhibition is a druggable MEK inhibitor resistance mechanism in KRAS-mutant lung cancer cells. Sci Transl Med 10: eaaq1093, 2018.

12. Arriazu E, Pippa R and Odero MD: Protein phosphatase 2A as a therapeutic target in acute myeloid leukemia. Front Oncol 6: 78, 2016.

13. Yu Y, Jin H, Xu J, Gu J, Li X, Xie Q, Huang H, Li J, Tian Z, Jiang $\mathrm{G}$, et al: XIAP overexpression promotes bladder cancer invasion in vitro and lung metastasis in vivo via enhancing nucleolin-mediated Rho-GDI $\beta$ mRNA stability. Int J Cancer 142: 2040-2055, 2018

14. Mizutani Y, Nakanishi H, Li YN, Matsubara H, Yamamoto K, Sato N, Shiraishi T, Nakamura T, Mikami K, Okihara K, et al: Overexpression of XIAP expression in renal cell carcinoma predicts a worse prognosis. Int J Oncol 30: 919-925, 2007.

15. Sung KW, Choi J, Hwang YK, Lee SJ, Kim HJ, Kim JY, Cho EJ, Yoo KH and Koo HH: Overexpression of X-linked inhibitor of apoptosis protein (XIAP) is an independent unfavorable prognostic factor in childhood de novo acute myeloid leukemia. J Korean Med Sci 24: 605-613, 2009.

16. Mansouri A, Zhang Q, Ridgway LD, Tian L and Claret FX: Cisplatin resistance in an ovarian carcinoma is associated with a defect in programmed cell death control through XIAP regulation. Oncol Res 13: 399-404, 2003.

17. Zhang S, Ding F, Luo A, Chen A, Yu Z, Ren S, Liu Z and Zhang L: XIAP is highly expressed in esophageal cancer and its downregulation by RNAi sensitizes esophageal carcinoma cell lines to chemotherapeutics. Cancer Biol Ther 6: 973-980, 2007.

18. Ren K, Gou X, Xiao M, He W and Kang J: Pim-2 cooperates with downstream factor XIAP to inhibit apoptosis and intensify malignant grade in prostate cancer. Pathol Oncol Res 25: 341-348, 2019.

19. Pagano MA, Tibaldi E, Molino P, Frezzato F, Trimarco V, Facco M, Zagotto G, Ribaudo G, Leanza L, Peruzzo R, et al: Mitochondrial apoptosis is induced by Alkoxy phenyl-1-propanone derivatives through PP2A-mediated dephosphorylation of Bad and Foxo3A in CLL. Leukemia 33: 1148-1160, 2019.

20. Eom T, Muslimov IA, Tsokas P, Berardi V, Zhong J, Sacktor TC and Tiedge H: Neuronal BC RNAs cooperate with eIF4B to mediate activity-dependent translational control. J Cell Biol 207: 237-252, 2014.

21. Ren K, Gou X, Xiao M, Wang M, Liu C, Tang Z and He W: The over-expression of Pim-2 promote the tumorigenesis of prostatic carcinoma through phosphorylating eIF4B. Prostate 73: 1462-1469, 2013.

22. Yang J, Wang J, Chen K, Guo G, Xi R, Rothman PB, Whitten D, Zhang L, Huang S and Chen JL: eIF4B phosphorylation by pim kinases plays a critical role in cellular transformation by $\mathrm{Abl}$ oncogenes. Cancer Res 73: 4898-4908, 2013.

23. Livak KJ and Schmittgen TD: Analysis of relative gene expression data using real-time quantitative PCR and the 2(-Delta Delta C(T)) method. Methods 25: 402-408, 2001

24. Leonard D, Huang W, Izadmehr S, O'Connor CM, Wiredja DD, Wang Z, Zaware N, Chen Y, Schlatzer DM, Kiselar J, et al: Selective PP2A enhancement through biased heterotrimer stabilization. Cell 181: 688-701.e16, 2020.

25. Soerdjbalie-Maikoe V, Pelger RC, Lycklama à Nijeholt GA, Arndt JW, Zwinderman AH, Bril H, Papapoulos SE and Hamdy NAT: Bone scintigraphy predicts the risk of spinal cord compression in hormone-refractory prostate cancer. Eur J Nucl Med Mol Imaging 31: 958-963, 2004.

26. Hwang SS, Chang VT, Alejandro Y, Mulaparthi S, Cogswell J, Srinivas S and Kasimis B: Study of hormone refractory prostate cancer: Hospital care and palliative care resource use at a VA medical center. Cancer Invest 22: 849-857, 2004.

27. Berruti A, Tucci M, Mosca A, Tarabuzzi R, Gorzegno G, Terrone C, Vana F, Lamanna G, Tampellini M, Porpiglia F, et al: Predictive factors for skeletal complications in hormone-refractory prostate cancer patients with metastatic bone disease. $\mathrm{Br}$ J Cancer 93: 633-638, 2005.

28. Inoue T, Segawa T, Kamba T, Yoshimura K, Nakamura E, Nishiyama $\mathrm{H}$, Ito $\mathrm{N}$, Kamoto $\mathrm{T}$, Habuchi $\mathrm{T}$ and Ogawa $\mathrm{O}$ : Prevalence of skeletal complications and their impact on survival of hormone refractory prostate cancer patients in Japan. Urology 73: 1104-1109, 2009.

29. Kirby M, Hirst C and Crawford ED: Characterising the castration-resistant prostate cancer population: A systematic review. Int J Clin Pract 65: 1180-1192, 2011. 
30. Antonarakis ES, Tagawa ST, Galletti G, Worroll D, Ballman K, Vanhuyse M, Sonpavde G, North S, Albany C, Tsao CK, et al: Randomized, noncomparative, phase II trial of early switch from docetaxel to cabazitaxel or vice versa, with integrated biomarker analysis, in men with chemotherapy-naïve, metastatic, castration-resistant prostate cancer. J Clin Oncol 35: 3181-3188, 2017.

31. de Bono JS, Logothetis CJ, Molina A, Fizazi K, North S, Chu L, Chi KN, Jones RJ, Goodman OB Jr, Saad F, et al: Abiraterone and increased survival in metastatic prostate cancer. $\mathrm{N}$ Engl J Med 364: 1995-2005, 2011.

32. Ryan CJ, Smith MR, de Bono JS, Molina A, Logothetis CJ, de Souza P, Fizazi K, Mainwaring P, Piulats JM, Ng S, et al: Abiraterone in metastatic prostate cancer without previous chemotherapy. N Engl J Med 368: 138-148, 2013.

33. Scher HI, Fizazi K, Saad F, Taplin ME, Sternberg CN, Miller K, de Wit R, Mulders P, Chi KN, Shore ND, et al: Increased survival with enzalutamide in prostate cancer after chemotherapy. $\mathrm{N}$ Engl J Med 367: 1187-1197, 2012.

34. Dong L, Zieren RC, Xue W, de Reijke TM and Pienta KJ Metastatic prostate cancer remains incurable, why? Asian J Urol 6: 26-41, 2019

35. Sweeney CJ, Chen YH, Carducci M, Liu G, Jarrard DF, Eisenberger M, Wong YN, Hahn N, Kohli M, Cooney MM, et al: Chemohormonal therapy in metastatic hormone-sensitive prostate cancer. N Engl J Med 373: 737-746, 2015.

36. Hoang DT, Iczkowski KA, Kilari D, See W and Nevalainen MT: Androgen receptor-dependent and -independent mechanisms driving prostate cancer progression: Opportunities for therapeutic targeting from multiple angles. Oncotarget 8: 3724-3745, 2017.

37. Bhardwaj A, Singh S, Srivastava SK, Arora S, Hyde SJ, Andrews J, Grizzle WE and Singh AP: Restoration of PPP2CA expression reverses epithelial-to-mesenchymal transition and suppresses prostate tumour growth and metastasis in an orthotopic mouse model. Br J Cancer 110: 2000-2010, 2014.

38. Bhardwaj A, Singh S, Srivastava SK, Honkanen RE, Reed E and Singh AP: Modulation of protein phosphatase 2A activity alters androgen-independent growth of prostate cancer cells: Therapeutic implications. Mol Cancer Ther 10: 720-731, 2011.

39. Pandey P, Seshacharyulu P, Das S, Rachagani S, Ponnusamy MP Yan Y, Johansson SL, Datta K, Lin MF and Batra SK: Impaired expression of protein phosphatase $2 \mathrm{~A}$ subunits enhances metastatic potential of human prostate cancer cells through activation of AKT pathway. Br J Cancer 108: 2590-2600, 2013.

40. Bluemn EG, Spencer ES, Mecham B, Gordon RR, Coleman I, Lewinshtein D, Mostaghel E, Zhang X, Annis J, Grandori C, et al: PPP2R2C loss promotes castration-resistance and is associated with increased prostate cancer-specific mortality. Mol Cancer Res 11: 568-578, 2013

41. Cristóbal I, González-Alonso P, Daoud L, Solano E, Torrejón B Manso R, Madoz-Gúrpide J, Rojo F and García-Foncillas J: Activation of the tumor suppressor PP2A emerges as a potential therapeutic strategy for treating prostate cancer. Mar Drugs 13: 3276-3286, 2015

42. Shah VM, English IA and Sears RC: Select stabilization of a tumor-suppressive PP2A heterotrimer. Trends Pharmacol Sci 41 . 595-597, 2020.
43. Zeng J, Liu W, Fan YZ, He DL and Li L: PrLZ increases prostate cancer docetaxel resistance by inhibiting LKB1/AMPK-mediated autophagy. Theranostics 8: 109-123, 2018.

44. Watt LF, Panicker N, Mannan A, Copeland B, Kahl RGS, Dun MD, Young B, Roselli S and Verrills NM: Functional importance of PP2A regulatory subunit loss in breast cancer. Breast Cancer Res Treat 166: 117-131, 2017.

45. Wu SY, Wen YC, Ku CC, Yang YC, Chow JM, Yang SF, Lee WJ and Chien MH: Penfluridol triggers cytoprotective autophagy and cellular apoptosis through ROS induction and activation of the PP2A-modulated MAPK pathway in acute myeloid leukemia with different FLT3 statuses. J Biomed Sci 26: 63, 2019.

46. Sangodkar J,Perl A, Tohme R, Kiselar J,Kastrinsky DB,Zaware N, Izadmehr S, MazharS, Wiredja DD, O'Connor CM, et al: Activation of tumor suppressor protein PP2A inhibits KRAS-driven tumor growth. J Clin Invest 127: 2081-2090, 2017.

47. Zhao Z, Kurimchak A, Nikonova AS, Feiser F, Wasserman JS, Fowle H, Varughese T, Connors M, Johnson K, Makhov P, et al: PPP2R2A prostate cancer haploinsufficiency is associated with worse prognosis and a high vulnerability to B55 $\alpha / \mathrm{PP} 2 \mathrm{~A}$ reconstitution that triggers centrosome destabilization. Oncogenesis 8: $72,2019$.

48. Remmerie M and Janssens V: PP2A: A promising biomarker and therapeutic target in endometrial cancer. Front Oncol 9: 462, 2019.

49. Wang J, Okkeri J, Pavic K, Wang Z, Kauko O, Halonen T, Sarek G, Ojala PM, Rao Z, Xu W and Westermarck J: Oncoprotein CIP2A is stabilized via interaction with tumor suppressor PP2A/B56. EMBO Rep 18: 437-450, 2017.

50. McClinch K, Avelar RA, Callejas D, Izadmehr S, Wiredja D, Perl A, Sangodkar J, Kastrinsky DB, Schlatzer D, Cooper M, et al: Small-Molecule activators of protein phosphatase 2A for the treatment of castration-resistant prostate cancer. Cancer Res 78: 2065-2080, 2018

51. Zhong Y, Tian F, Ma H, Wang H, Yang W, Liu Z and Liao A: FTY720 induces ferroptosis and autophagy via PP2A/AMPK pathway in multiple myeloma cells. Life Sci 260: 118077, 2020.

52. Meng G, Wang W, Chai K, Yang S, Li F and Jiang K: Combination treatment with triptolide and hydroxycamptothecin synergistically enhances apoptosis in A549 lung adenocarcinoma cells through PP2A-regulated ERK, p38 MAPKs and Akt signaling pathways. Int J Oncol 46: 1007-1017, 2015.

53. Galletti G, Leach BI, Lam L and Tagawa ST: Mechanisms of resistance to systemic therapy in metastatic castration-resistant prostate cancer. Cancer Treat Rev 57: 16-27, 2017.

54. Amantana A, London CA, Iversen PL and Devi GR: X-linked inhibitor of apoptosis protein inhibition induces apoptosis and enhances chemotherapy sensitivity in human prostate cancer cells. Mol Cancer Ther 3: 699-707, 2004.

This work is licensed under a Creative Commons Attribution-NonCommercial-NoDerivatives 4.0 International (CC BY-NC-ND 4.0) License. 